\title{
PRECARIZAÇÃO DA DOCÊNCIA: OS DIREITOS DA PERSONALIDADE FRENTE AO TRABALHO REMOTO
}

Leda Maria Messias da Silva ${ }^{1}$ Nadine Girardi Alves ${ }^{2}$

RESUMO: O trabalho docente já se encontrava precarizado por condições desfavoráveis, intensificadas pela implementação do trabalho remoto, devido à pandemia. Assim, valendo-se da metodologia hipotético-dedutiva, a pesquisa objetiva analisar tais condições nas instituições privadas de ensino superior, e os impactos que a mudança para o meio virtual podem acarretar aos direitos da personalidade dos professores, tais como o direito à imagem, à privacidade, e à liberdade de cátedra. Constata-se, por fim, que convém às instituições de ensino que observem estritamente a garantia de referidos direitos, sendo imprescindível a adequação das normas jurídicas e a correta execução dos contratos individuais de trabalho.

PALAVRAS-CHAVE: teletrabalho; ensino remoto emergencial; direitos da personalidade; educação superior privada; pandemia.

\section{PRECARIZATION OF TEACHING: PERSONALITY RIGHTS FACING REMOTE WORK}

ABSTRACT: Teaching work was already precarious by unfavorable conditions, intensified by the implementation of remote work, due to the pandemic. Thus, using the hypotheticaldeductive methodology, the research aims to analyze such conditions in private institutions of higher education, and the impacts that the change to the virtual environment can have on the personality rights of teachers, such as the right to image, privacy, and academic freedom. Finally, it appears that it is appropriate for educational institutions to strictly observe the guarantee of these rights, and it is essential to adapt the legal rules and the correct execution of individual employment contracts.

KEY-WORDS: telecommuting; emergency remote learning; personality rights; private higher education; pandemic.

\section{INTRODUÇÃO}

O uso das tecnologias de informação e comunicação nas práticas do trabalho docente foram intensificadas em vista da necessidade de adoção do teletrabalho através do ensino remoto como meio de combate à disseminação da pandemia, sendo inegável que esta situação

\footnotetext{
${ }^{1}$ Pós-doutora em Direito do Trabalho pela Universidade de Lisboa-Portugal; Doutora e Mestre em Direito do Trabalho pela PUC/SP; Professora do Mestrado e Doutorado em Ciências Jurídicas na Universidade UniCesumar e da Pós-Graduação e Graduação na Universidade Estadual de Maringá/PR (UEM); Ex-professora da Universidade Cândido Mendes e Moacyr Sreder Bastos no Rio de Janeiro/RJ; Pesquisadora do CNPQ e Instituto Cesumar de Ciência, Tecnologia e Inovação; Bolsista produtividade em pesquisa do ICETI; Advogada Trabalhista.

${ }^{2}$ Mestranda em Direitos da Personalidade pelo Programa de Pós-Graduação em Ciências Jurídicas Universidade Cesumar - UNICESUMAR; Bolsista pelo Instituto Cesumar de Ciência, Tecnologia e Inovação - ICETI; Graduada em Direito pela Pontifícia Universidade Católica do Paraná - PUCPR.
} 
agravou aspectos pré-existentes que já vinham precarizando o trabalho dos professores. Diante disso, a partir da metodologia científica hipotético-dedutiva, a presente pesquisa se propõe a analisar algumas das principais condições que precarizam o trabalho docente, especificamente, nas instituições de ensino superior privadas, e refletir sobre os impactos que esta transposição abrupta para plataformas digitais gerou aos direitos da personalidade inerentes aos docentes, tais como o direito à imagem, à intimidade, à privacidade e proteção de dados, e à liberdade de cátedra.

Em um primeiro momento, analisar-se-á questões anteriores à pandemia, como o "empresariamento da educação" e o temor ao desemprego, com a crescente do ensino à distância em comparação à fragmentação do trabalho do professor, as quais já tornava desfavorável a atividade laborativa dos professores. Após, o estudo sinaliza questões que agravaram a situação anterior, com o acontecimento inesperado da pandemia, tais como a falta de delimitação do tempo e do espaço de trabalho, com dificuldades à desconexão, além da necessidade de qualificação tecnológica e o custeio de utilidades. Por fim, a pesquisa se dedica a refletir sobre os impactos que o trabalho por plataformas digitais, com a gravação de aulas, pode acarretar aos direitos da personalidade dos professores, seja ao direito de imagem, de privacidade e proteção de dados, ou até mesmo à liberdade de cátedra.

A pesquisa se justifica uma vez que se mostra necessário um olhar atento sobre os impactos que as práticas do teletrabalho, na modalidade de educação remota emergencial, podem gerar aos direitos da personalidade dos professores e professoras, assim como aos demais direitos assegurados pelo ordenamento jurídico, tendo em vista o agravamento da precariedade que já assolava a classe dos trabalhadores da educação, especialmente pela relevância que os profissionais da educação possuem para todo o desenvolvimento da sociedade. Sabe-se e reconhece-se o direito e até dever do empregador em, por questões de saúde pública, adotar o trabalho remoto, porém, este não pode servir de "desculpas" para durante e após o período da pandemia, haver o abuso do uso de imagens e de gravações do trabalho docente, excesso de alunos em salas virtuais, acarretando um volume maior de trabalho extraclasse, bem como, desrespeito ao direito à desconexão e ao descanso do docente, levando-o à extensas e contínuas jornadas de trabalho.

\section{PRECARIZAÇÃO DO TRABALHO DOCENTE: do presencial ao remoto}


O trabalho é considerado uma das formas mais importantes de realização da pessoa humana, diante da disponibilidade de tempo, e da dedicação intelectual ou física que se deposita na prática laborativa ao longo da vida, além de assumir "o caráter de ser o mais relevante meio garantidor de um mínimo de poder social à grande massa da população" (GODINHO, 2007, p. 16). Por sua vez, a essencialidade do trabalho do professor decorre, principalmente, de sua importância para a educação e para a formação das demais profissões:

O professor foi uma das primeiras profissões do mundo. Todas as outras especialidades e habilidades técnicas só puderam existir quando passaram a contar com professores para ensinar-lhes a profissão a ser desempenhada. (SILVA; PEREIRA, 2013, p. 50)

Em vista disso, o trabalho docente é, via de regra, marcado por significativas modificações em conformidade com os dinamismos históricos e sociais, denotando-se que, atualmente, a tecnologia vem influenciando o modo de realização da atividade laborativa dos professores, assim como nas demais relações de trabalho.

É inegável que a intensificação do uso, para o ensino, de mecanismos digitais e da internet, se deu pela ocorrência da pandemia. Isso porque, o cenário de disseminação mundial de uma doença altamente contagiosa e letal, como a causada pelo coronavírus, exigiu a imposição de medidas de isolamento e distanciamento social, tais como a suspensão de aulas e estágios presenciais, bem como o fechamento temporário do ambiente físico das instituições de ensino, fazendo-se necessária a busca por alternativas rápidas para a continuidade das atividades educacionais.

Nesse ponto, as tecnologias da informação e comunicação e o uso de plataformas digitais possibilitaram o implemento de novas formas de trabalho, como o teletrabalho, o trabalho remoto, e o home office, além de potencializar certas formas de ensino, como o ensino remoto e o ensino híbrido, os quais passaram a ser adotados diante da crise de saúde instalada.

Ocorre que esta transposição abrupta das atividades educacionais, do meio presencial para o virtual, importa em consequências distintas para os mais diversos níveis de educação, desde a educação básica até a educação superior, dadas as especificações e necessidades de cada fase do ensino, sendo crescente a preocupação com a qualidade educacional que os educandos passaram a receber desde a instalação da educação remota como o meio emergencial e alternativo de aprendizagem, seja pela falta de acesso à internet, pela falta de 
recursos tecnológicos necessários para o acompanhamento de aulas, ou até mesmo pela incompatibilidade de atividades com a modalidade online.

Além disso, as dificuldades enfrentadas pelos professores também variam de acordo com o âmbito educacional no qual atuam, embora seja fato que a nova realidade do ensino consistiu em uma mudança repentina, que atingiu, de modo geral, sobremaneira a atividade docente, a qual passou a ser desempenhada preponderantemente pelo meio virtual, agravando as dificuldades pré-existentes e já experimentadas pelos profissionais da área da educação:

embora a precarização da docência não seja uma situação nova em si, é inegável que o atual contexto pandêmico, além de potencializar e dar força às adversidades do quadro predecessor, tem também ensejado novas dificuldades, que se somam àquelas verificadas ao longo dos últimos anos. (DELGADO; PESSANHA; ROCHA, 2021).

Importante salientar que o presente estudo visa, de forma específica, analisar as principais nuances impostas ao trabalho dos docentes das instituições de ensino superior privadas, uma vez que o labor de referidos profissionais já apresentava fragilidades próprias, como por exemplo, causadas pelo "empresariamento da educação" (GEMELLI; CERDEIRA, 2020, p. 115), e pela sobrecarga de trabalho em comparação às reduções de remuneração e benefícios, situações estas que foram acentuadas pela migração contundente para o ensino remoto, e pelos novos formatos adotados para a prestação laborativa.

Assim, é possível afirmar que o advento da pandemia contribuiu para o fortalecimento da precarização do trabalho docente, em especial no nível superior e privado, somando-se às condições desfavoráveis anteriores, as quais serão abordadas mais adiante, tendo em vista a importância de suas análises e seus impactos para a busca da hígida proteção dos direitos da personalidade dos trabalhadores da educação, em seu meio ambiente de trabalho. Embora não se negue a necessidade da implantação do home office e a sua utilidade diante da situação imposta para a proteção da saúde em geral, também, não se pode negar que de certa forma, isso serviu como um meio de acelerar a precarização, pois imposto ao trabalhador docente, jornadas extensas, uso de sua imagem e dados, e salas virtuais sem limites, com algumas possuindo quase cem alunos, o que acarreta maior trabalho ao docente em suas tarefas de correções de provas e trabalhos.

2.1 Aspectos do trabalho docente nas instituições privadas de educação superior 
A precarização da atividade de trabalho dos professores da educação superior privada, como dito alhures, não teve início por conta da pandemia, embora tenha sido potencializada por ela, uma vez que se trata de um quadro de desestímulo que vem se desenvolvendo lenta e vagarosamente, em prejuízo de profissionais essenciais para o desenvolvimento individual e coletivo, assim, assemelhando-se à situação dos demais trabalhadores:

\begin{abstract}
a precarização do trabalho coloca-se como uma realidade com a qual se tem convivido, crescendo substancialmente e de maneira embasada, sobretudo, nos moldes atuais de produção do capitalismo de finanças e do sistema toyotista, que extrapola o âmbito das fabricas e chega a muitos outros espaços de atuação trabalhista [...] Dentre as profissões tradicionais, e que vêm sendo afetadas por essas metamorfoses, destaca-se a carreira docente. (PESSANHA, 2020, p. 228)
\end{abstract}

Por outro lado, a falta de apoio do Estado aos discentes para se manterem no ensino remoto (falta de internet ou eficácia da internet, falta de computadores, apoio econômico etc.), medida emergencial adotada pelo risco de contágio de coronavírus, somado à inadimplência causada pelo desemprego e pela insegurança financeira, implementam o crescente abandono do ensino superior.

Esse cenário diz respeito a uma das condições desfavoráveis e de insegurança impostas ao trabalho do docente no setor privado, por representar riscos ao trabalho dos professores, uma vez que pode ocorrer o atraso nos pagamentos ou a diminuição de suas remunerações, podendo resultar, inclusive, na finalização massiva de contratos de trabalho. Embora, não se possa olvidar que sem custos com energia, água, limpeza etc., correspondente aos períodos de plena atividade presencial, mas aumentando o número de alunos nas aulas remotas, não se justifica o fator financeiro para a rescisão contratual de professores no período da pandemia, pois de certa forma há uma compensação de custos.

Ainda, tal qual os mais variados setores privados de trabalho, há o temor ao desemprego quando se trata do trabalho dos professores, considerando as tendências atuais de redução de custos e barateamento da mão-de-obra, aumento do ensino à distância clássico, o EAD, em detrimento da contratação de profissionais mais qualificados e do ensino presencial, ainda que em épocas não pandêmicas. Assim, conforme a estudiosa Vanessa Pessanha (2020, p.224):

um dos fenômenos observados na área é a ruptura contratual em massa de docentes mais antigos(as) e mais qualificados(as) na carreira universitária. Essa ocorrência tem sido associada aos salários de maior monta, sendo as vagas reduzidas - com concentração de trabalho para poucos profissionais e que, por vezes, sequer têm 
afinidade com determinados componentes curriculares, mas que se sentem pressionados a assumi-los com receio de serem os próximos na lista de despedida.

Apesar do valor social atribuído ao trabalho, por ser essencial para o desenvolvimento do papel da pessoa como ser social, a necessidade para a subsistência aliada à diminuição da oferta de empregos na área da educação, que corresponda à qualificação e à carreira almejada, faz com que muitos profissionais aceitem as condições que lhe são impostas, em quase que completa submissão, sem poder de debate frente às alterações contratuais feitas por meio de termos aditivos, e que venham a prejudicar o trabalhador por retirarem direitos, reduzirem benefícios e modificarem questões essenciais para a atividade, cujos termos haviam sido acordados inicialmente de forma diversa (PESSANHA, 2020, p. 225). Neste sentido:

A condição na qual se forma o contrato e se remunera o docente em educação a distância é totalmente dominada pela instituição, e, invariavelmente, representa uma condição de exploração do profissional e de inferiorização da educação a distância, servindo ao estabelecimento de marketing de rapidez, comodidade e baixo preço que acompanha o ensino a distância. (OLIVEIRA; LEMOS JR, 2018, p. 32)

Além da situação descrita, há de se considerar o advento da tendência atual, nomeada por estudiosos de "mercantilização e de empresariamento da educação" (GEMELLI; CERDEIRA, 2020, p. 115), como uma condição pré-existente de precarização do trabalho docente em instituições privadas de educação superior.

Referida tendência é influenciada pelo sistema capitalista e por "princípios neoliberais - lógica da concorrência, desempenho, produtividade -, em sua interface com as novas relações de trabalho - flexibilidade, empresariamento de si, investimento em capital humano" (KLAUS, 2017, p. 354), ou seja, as instituições privadas de ensino superior passaram a atuar sob uma lógica empresarial e produtivista, em resumo, visando mais o lucro do que a qualidade da educação e do meio ambiente de trabalho para os docentes e demais empregados. Os professores passam a ser horistas e o pessoal administrativo, descartável, ambos, rapidamente, substituíveis.

Por estar inserida no sistema de capitalismo neoliberal, a educação passou a ser mercantilizada, posto que, de um lado, os alunos passaram a ser identificados como clientes, enquanto que de outro, o professor passou a figurar somente como um facilitador da entrega do serviço/produto comercializado, que é o ensino.

Ainda, destaca-se que esse movimento modificador dos sujeitos da relação "educador-educando" e da relação "empregado-empregador", fomenta a busca pela redução 
de custos, fortalecendo os aspectos contratuais desfavoráveis aos professores e o temor ao desemprego, mencionados anteriormente, uma vez que passaram a ser visados os profissionais que entreguem produtividade sendo mão-de-obra "mais barata", do que aqueles mais qualificados e experientes. No entendimento das estudiosas Catia Eli Gemelli e Luísa Cerdeira (2020, p. 119):

Um forte discurso que ancora o processo de empresariamento da educação é o de que o privado é mais eficiente que o público, a partir da lógica gerencial da busca por eficiência, eficácia e produtividade. Em tempos de escassez de recursos e de cobrança de soluções rápidas para o enfrentamento da crise provocada pela COVID19 , há o risco de um fortalecimento ainda maior dessa visão gerencial.

Vale ressaltar que antes mesmo da crise de saúde vivenciada nos últimos anos, a imposição tecnológica ao trabalho dos professores ocorria por meio do crescimento do ensino à distância, modalidade de ensino remoto e assíncrono, também conhecido como EAD, o qual já vinha sendo implementado pelas universidades privadas, cujas características se encaixam no interesse de mercantilização e empresariamento da educação, sendo cabível intuir que:

instituições de ensino superior privadas encontraram na pandemia o momento adequado para a imposição das ferramentas virtuais no processo do trabalho docente, promovendo uma resposta à crise sanitária ao mesmo tempo em que atendiam a um projeto preexistente de produtividade, redução de custos [...] atendendo ao imperativo gerencial de corte de gastos, essas instituições têm intensificado ainda mais o enxugamento do quadro docente. (DELGADO; PESSANHA; ROCHA, 2021).

O ensino à distância, portanto, se mostrou bastante atrativo para a novo formato organizacional em que se insere o ensino superior privado, uma vez que oferece vantagens condizentes com o ideário do capitalismo neoliberal, mesmo que importe em fragilização do ensino, com a precarização e aumento da exploração do trabalho docente. Dessa maneira, convém pontuar que a modalidade, não raro, tem sido objeto de controvérsias e debates.

Por um lado, defende-se o ensino à distância para a educação superior sob a justificativa de universalização do ensino profissionalizante, gerando oportunidade para aqueles que não poderiam ter acesso de forma presencial, além de oferecer maior flexibilidade e autonomia ao aluno, para regular sua própria aprendizagem.

Em contrapartida, embora seja uma prática inovadora, seu implemento deve se dar com cautela e ressalvas, posto que se critica a qualidade da educação oferecida à distância, uma vez que se trata de um "ensino padronizado e massificado, em salas de aula virtuais que comportam uma quantidade de estudantes cada vez maior, associado a um trabalho fragmentado" (DELGADO; PESSANHA; ROCHA, 2021). 
Assim, operando de acordo com um sistema voltado para o aumento de capital, com a diminuição de gastos, facilmente se compreende a opção das instituições privadas de ensino superior pelo projeto de educação à distância: a gravação de uma aula pode ser reproduzida inúmeras vezes, de qualquer localidade, sem que sejam investidos grande monta de valores em estrutura física para comportar tantos alunos, gastos com eletricidade, equipamentos, funcionários auxiliares para serviços gerais etc, além de resultar em prejuízo ao trabalho docente, conforme apontam Gabriela Delgado, Vanessa Pessanha e Ana Luísa Rocha (2021):

\begin{abstract}
O próprio modelo de ensino virtual demanda menos professores, tendo a experiência da pandemia evidenciado o "ensalamento virtual" como estratégia comercialmente vantajosa às instituições, já que torna possível concentrar, em uma mesma aula, centenas de alunos - por vezes de diferentes semestres e cursos -, sem as limitações do espaço físico.
\end{abstract}

Além disso, a fragmentação do trabalho do professor é outra questão preocupante em relação à expansão do ensino à distância, que poderia ser potencializada com o ensino remoto, haja vista o potencial de reforçar as adversidades já explanadas, que dizem respeito aos aspectos contratuais (alteração prejudicial de contrato de trabalho, com a redução de remuneração ou benefícios), além de importar na desvirtuação do sentido da docência.

Isso porque, com a fragmentação do papel docente, as atividades desempenhadas por um professor podem passar a ser realizadas por outros tantos professores, em complementariedade, constituindo-se a chamada "polidocência"3. Por certo, fragmentar a atividade dos professores, mesmo que em virtude de certa colaboratividade, importaria em alterar a finalidade da prática docente, tendo em vista que o professor é um profissional completo, que exerce diversas atribuições em prol de um sentido maior, assim explicado pelas educadoras Renata Carmo e Aléxia Pádua Franco (2019, p. 10):

Ser professor é desempenhar uma atividade profissional que exige qualificação para o saber disciplinar e o saber pedagógico, pois ensinar, além de ser um ato social e histórico, implica a formação de pessoas para compreender e interpretar informações em um processo para a construção de novos conhecimentos.

A mencionada desvirtuação da finalidade educativa para dar lugar à lucratividade, e a fragmentação da docência, motivou o "afastamento do docente do seu papel formador, que

\footnotetext{
3 A polidocência consistiria na distinção entre os professores conforme as atividades desempenhadas. Descritivamente, haveria a figura do "professor-responsável, que se responsabiliza pelo planejamento de uma disciplina; professor-conteudista, que elabora materiais didáticos; professor-formador, que forma e acompanha os tutores; ou professor-tutor, que faz a mediação das interações educador-educando. Atribuições docentes tão específicas e interdependentes entre si instituíram a polidocência, forma de trabalho docente executado de modo colaborativo e fragmentado" (MILL, 2012 apud CARMO, FRANCO, 2019, p. 4).
} 
não pode ser exercido em sua essência dentro de uma relação mercadológica e utilitarista" (Gaulejac, 2007; Medeiros e Siqueira, 2019 apud RABELLO; SOUZA; MARTINS, 2020, p. 103), sendo certo que referidas práticas dificultam tanto a aprendizagem quanto a própria atividade de ensinar.

Indubitavelmente, o trabalho do professor deve ser considerado para além da entrega de um serviço educacional qualquer, a ser executado por força contratual, e voltado para uma maior quantidade de alunos. Isso porque, a função formadora do docente se consubstancia, em especial, pelo contato mais direto com os discentes, já que através da observação inferem-se as dificuldades e os graus de aprendizagem e compreensão do conteúdo ministrado, ou seja, a proximidade entre educadores e educandos é de grande importância para a qualidade da educação ofertada, bem como para a dificuldade do trabalho desempenhado pelos professores.

2.2 O trabalho remoto na pandemia e o agravamento das condições desfavoráveis do trabalho docente

É notório que a crise sanitária vivenciada nos últimos anos impôs uma readequação dos comportamentos sociais, como forma de conter a rápida contaminação pelo vírus SARSCoV-2, o qual provou o adoecimento e a morte de milhões de pessoas ao redor do globo. Assim, a ocorrência da pandemia exigiu a tomada de medidas emergenciais de isolamento e distanciamento social, impondo-se restrições às mais diversas práticas sociais, inclusive ao modo de realização do trabalho e do ensino, em resguardo da saúde de toda a coletividade.

De fato, antes mesmo do exercício das profissões e da importância do ensino, o zelo pela vida e pela saúde, em prevenção à uma doença repentina e letal como o coronavírus, fezse urgente. Além disso, para que fosse possível a manutenção dos empregos dos professores e a continuidade das atividades educacionais, mostrou-se acertada a migração das atividades docentes para o meio virtual, com a implementação do teletrabalho, na modalidade de ensino remoto emergencial.

Contudo, apesar de representar medidas essenciais ao enfrentamento da pandemia, é importante pontuar que o panorama exposto intensificou as práticas virtuais no meio educativo, de modo a influenciar no agravamento da precarização do trabalho dos professores e professoras, mais especificamente pela mudança abrupta do ensino (e da atividade docente) para o meio digital, uma vez que os professores precisaram "reconfigurar toda a sua rotina 
para fazer funcionar o seu trabalho em uma modalidade absolutamente nova" (RABELLO; SOUZA; MARTINS, 2020, p. 102) ${ }^{4}$.

Apesar do viés suplementar atribuído ao ensino remoto para manutenção das práticas educacionais em tempos de pandemia, ao passo que as aulas presenciais e o contato com os alunos passaram a ocorrer quase que integralmente pelo meio virtual, o professor vem ensinando pelas telas de aparelhos eletrônicos, através de plataformas digitais, muitas vezes por longos períodos, sem atividades assíncronas, prejudicando a sua saúde, e até dos alunos por permanecerem em uma única posição por muito tempo e, geralmente, sem os instrumentos ergonômicos necessários.

Além da modificação observada na prática do ensino, os professores passaram a realizar as demais atividades laborativas extraclasse de dentro de suas próprias residências, ou de ambientes particulares, como a elaboração e correção de avaliações, bem como atividades administrativas, provocando a ocorrência de outros aspectos desfavoráveis ao trabalho docente. A mistura entre o ambiente laborativo e o ambiente doméstico ensejou dificuldades antes não experimentadas pelos professores e professoras, sendo certo que a carga de trabalho permaneceu a mesma, ou ainda mais excessiva, com cobranças ainda mais contundentes de desempenho e produtividade e a qualquer hora.

Ainda, haja vista ser inegável que os meios virtuais de trabalho possibilitam o encurtamento do tempo de realização de tarefas, houve uma aceleração do ritmo de trabalho, seja para atender as demandas recebidas em horários irregulares, seja para responder aos emails, mensagens instantâneas em whatsapps, telegram etc, gerando dificuldades para que os profissionais delimitem jornadas e se desconectem do trabalho.

Diante disso, a falta de distinção entre o tempo e os espaços laborativos e particulares dificultam a desconexão das atividades de trabalho, em prejuízo dos períodos de descanso, de lazer, e das demais atividades inerentes à vida privada das pessoas que também são

\footnotetext{
${ }^{4}$ Para melhor ilustrar a passagem do ensino presencial para o remoto, anota-se o seguinte trecho, bastante descritivo desta situação: "Diante da imposição de medidas que passam principalmente pela restrição de contato, dada pelo distanciamento e isolamento social, coube então às instituições de ensino providenciar grandes plataformas virtuais que viabilizassem o processo de ensino-aprendizagem, indo desde a possibilidade de compartilhar e corrigir tarefas, até o uso dos aplicativos de vídeo-chamadas, de forma que os alunos e professores pudessem conversar sincronicamente, visando aproximar essa experiência, o máximo possível, da experiência presencial. As ferramentas assíncronas, já amplamente utilizadas desde antes da crise, como é o caso do whatsapp, passaram a ser ainda mais exploradas: o fato de estar permanentemente em casa parece dissolver as barreiras que dividem a vida pessoal da profissional, produzindo uma sensação de que o trabalhador deveria estar sempre à disposição da instituição e dos seus alunos, o que evidencia ainda mais uma relação cliente-fornecedor, bem distante da lógica que permeia a relação educador-educando" (RABELLO; SOUZA; MARTINS, 2020, p. 103).
} 
professoras. É notável que a realidade do trabalho docente se tornou ainda mais desestimulante e diversa daquela condição idealizada para que o educador efetue suas atividades de forma digna, sem contar a evidente afronta ao seu direito da personalidade à saúde, face à ausência de descanso.

Portanto, além do panorama predecessor exposto, produto do temor ao desemprego, aliado ao fenômeno de "empresariamento do ensino", somam-se novas condições desenvolvidas pela pandemia, em virtude da aplicação do ensino remoto emergencial sem limites e sem intervalos, e da implantação, às pressas, de um modelo de trabalho remoto, apesar de adotados de forma urgente e necessária, mas que extrapolam o necessário e perpassam ao ambiente laboral híbrido, com filmagens de sala de aula e o professor se desdobrando em muitos, para atender quem está presencial e quem está no virtual. O agravamento da precarização do trabalho docente, em contrariedade aos direitos fundamentais e da personalidade assegurados para os educadores, neste cenário, é evidente. Em resumo, a situação vivenciada pelos professores, em tempos de pandemia, com a readaptação da própria profissão e do ensino, foi descrita da seguinte forma:

Toda essa conjuntura requer dos professores adaptação às exigências dos novos
tempos, domínio dos recursos tecnológicos, novos conhecimentos, desenvolvimento
de competências para administrarem o tempo na vivência "sem fronteiras" do home
office, a ministrarem aulas criativas, performáticas, que possam prender a atenção
dos alunos, que possam motivá-los a se adaptarem ao formato remoto, a obterem
ótimos rendimentos. Além disso, a exigência de competências e habilidades para
gerirem os conflitos e adversidades próprias dessa relação professor-aluno, ensino-
aprendizagem, espaço acadêmico-espaço pessoal, vida privada-vida pública
viabilizadas pelo aparato tecnológico, reconfigurando a esfera da intimidade ao
fundir os espaços, o público e o privado. (RABELLO; SOUZA; MARTINS, 2020,
p. 107)

Assim sendo, destaca-se que muitos professores, antes acostumados com o exercício presencial das suas atividades de trabalho, precisaram aprender e se familiarizar com o manuseio de ferramentas, multimídias e plataformas digitais, sendo certo que essa busca por qualificação profissional e tecnológica demandou esforços dos próprios professores, posto que muitas universidades sequer ofereceram cursos capacitantes, além de não ter havido um tempo de adaptação, porque essa mudança aconteceu repentinamente, por conta da emergência de saúde.

Ademais, neste mesmo sentido, deve-se considerar o custeio próprio, de todo o aparato para a prática da atividade laborativa do professor, incluindo a confecção de uma estrutura física em suas residências, com a aquisição de melhores equipamentos tecnológicos, 
para comportar o espaço de teletrabalho, além de ser inegável o aumento dos gastos domiciliares, pelo maior uso da energia, contratação de internet de melhor qualidade etc.

Em suma, os docentes vivenciaram o aumento de contas, e a incorporação de certos custos, em decorrência do teletrabalho para a execução das suas atividades laborativas, enquanto que, em diversos casos, a remuneração recebida não comportou os reajustes ou reembolsos por estes gastos e atividades extras demandadas pelo ensino remoto, embora estas utilidades devam ser previstas em contrato, não integrando a remuneração do empregado, de acordo com o artigo 75-D, da Consolidação das Leis do Trabalho (CLT, Decreto-Lei $\mathrm{n}^{\circ}$ $5.452 / 1943)$.

Apesar de representar medidas transitórias e urgentes, tomadas por força da impossibilidade de realização do cronograma de ensino de forma presencial, diante da necessidade de restrições de contato interpessoal para prevenir a disseminação da pandemia, impera ressaltar que houve a incorreta ou inadequada pactuação das condições de trabalho dos professores a serem exercidas no modelo de trabalho remoto ou de teletrabalho, empregados em vista da adoção do ensino remoto emergencial, diante do que foi exposto. Isso porque, ora o abuso e as exigências exageradas de um labor sem intermitência, ora porque, ao reduzir as restrições, a precarização foi levada para a sala de aula, com as filmagens e a falta de respeito à liberdade de cátedra do docente.

Muitos professores passaram a trabalhar de forma remota sem qualquer alteração contratual prévia ${ }^{5}$, ou feitas de forma inadequada, sem que se avaliassem as demandas específicas e peculiaridades existentes no ensino remoto, as quais se distinguem do ensino presencial, ou até mesmo do ensino híbrido, ou seja, o professor continuou a receber a mesma remuneração, embora tenha passado a exercer sua profissão em condições completamente diferentes e, em diversos aspectos, desfavoráveis e cansativo.

Com efeito, após o cenário emergencial, as práticas relacionadas ao ensino virtual à distância, tendem a ser ampliadas e utilizadas em larga escala pelas instituições de ensino, além das novas práticas de trabalho remoto, como o home office e o teletrabalho, afinal se mostrou possível (mas não necessariamente ideal) que se eduque e que se trabalhe por meio

\footnotetext{
${ }^{5}$ Embora não esteja mais vigente, a falta da correta regulamentação das novas condições de trabalho impostas pela pandemia pode ser justificada, também, pela normatização emergencial que facultou aos empregadores a possibilidade de "alterar o regime de trabalho presencial para o teletrabalho, o trabalho remoto ou outro tipo de trabalho a distância e determinar o retorno ao regime de trabalho presencial, independentemente da existência de acordos individuais ou coletivos, dispensado o registro prévio da alteração no contrato individual de trabalho" (BRASIL, 2020, grifo nosso), conforme o artigo $4^{a}$ da Medida Provisória $n^{\circ}$ 927, de 2020, que elencou as medidas de enfrentamento a serem tomadas diante da calamidade pública causada pelo coronavírus.
} 
destes novos modelos digitais. Há que se ter em mente a sua utilidade para o momento de pandemia, porém, com as suas limitações para além da pandemia.

Embora sejam distintas entre si, o ponto comum entre todas essas práticas é a alteração substancial do trabalho docente pelo implemento do uso predominante das tecnologias, com o aumento da exploração do trabalho, ante as necessidades de cumprimento de metas, de alta produtividade, de requalificação profissional etc, ou seja, as relações de trabalho dos professores "adquiriram maior grau de complexidade e de dificuldade, atualmente, quer pelo aumento das tarefas que são cobradas, sem a correspondente contraprestação financeira, quer pela rotatividade, quer pelo desrespeito aos direitos da personalidade que são atingidos" (SILVA; PEREIRA, 2013, p. 57).

Enfim, as fragilidades enfrentadas pela docência, anteriores e aquelas surgidas pela pandemia, não se exaurem somente pelos pontos sinalizados no presente estudo, mas é possível inferir que o trabalho do professor nas instituições de ensino superior privado se tornou ainda mais precarizado e exaustivo, representando riscos à violação de direitos, como o de imagem, da privacidade, e da liberdade de cátedra, entre outros direitos fundamentais e da personalidade das pessoas que trabalham e dependem do ensino, conforme se refletirá a seguir.

\section{DIREITOS DA PERSONALIDADE DOS PROFESSORES}

O regime de trabalho emergencial instituído pela pandemia, seja o teletrabalho, na modalidade de trabalho remoto, ou ainda o trabalho híbrido, afetaram sobremaneira a atividade dos professores e professoras nas instituições privadas de ensino superior, cujas condições já se mostravam prejudiciais, como aludido anteriormente.

Em vista disso, e pela potencialização das práticas virtuais de ensino, faz-se necessário avaliar os impactos que o agravamento desses aspectos desfavoráveis gerou ao meio ambiente de trabalho dos professores, no que tange aos seus direitos da personalidade, dentre os quais se pode mencionar o direito à imagem, à privacidade e proteção de dados, e até mesmo o direito fundamental de liberdade de cátedra, assegurado constitucionalmente à classe dos educadores.

3.1 Meio ambiente de trabalho do professor: plataformas digitais e a sala de aula gravada 
Sabe-se que a migração súbita na forma de ensino, do meio presencial para o meio digital exigiu várias adaptações por parte dos estudantes, contudo, representou substancial transformação à prática e ao meio ambiente de trabalho de todo o corpo docente das instituições de ensino superior privado.

De fato, não só o modo de execução como também o meio ambiente de trabalho dos professores absorveu os impactos de referidas modificações, sendo inegável que suas próprias residências ou o local onde exercem suas atividades laborativas podem constituir este meio ambiente de trabalho, onde deve ser garantida a saúde, segurança e a dignidade dos docentes, enquanto pessoas trabalhadoras.

Com efeito, a atividade docente passou a ser realizada por meio de plataformas digitais, de ferramentas eletrônicas e de multimídias, de modo que o trabalho do professor passou a depender, quase que integralmente, das tecnologias da informação e comunicação, dispensando a necessidade de comparecimento ao ambiente físico das instituições de ensino.

Passou-se a ministrar aulas, aplicar avaliações, desenvolver atividades etc, de dentro de casa (apesar dos apontamentos feitos acerca do custeio de utilidades para tanto), sendo certo que o lar se tornou, também, o meio ambiente de trabalho do professor.

Isso porque, segundo Álvaro Mello (1999, p. 4) “a área física onde tradicionalmente se trabalha não é mais uma entidade tangível, com fronteiras bem definidas, baseadas em regras e observação visual do processo do trabalho".

Indubitavelmente, qualquer que seja o local onde se execute o trabalho docente, inclusive no meio digital e no interior de residências próprias, os direitos da personalidade devem ser assegurados, assim como os demais direitos fundamentais atinentes à pessoa humana, uma vez que:

Os direitos individuais, ou seja, os Direitos da Personalidade devem ser observados sempre em favor da proteção dos trabalhadores, afinal é justamente na execução dos contratos de trabalho, cuja consolidação dos trabalhadores se dá de forma pessoal, é que os mesmos adquirem um novo status, e dentro desse novo status podem ter seus direitos personalíssimos, invariavelmente, violados, seja por extrapolação da finalidade contratual, seja por qualquer outra eventualidade que agrida os direitos fundamentais do homem, na espécie trabalhador. (SILVA; ZANIN, 2012).

De antemão, urge indicar que, recentemente, com o avanço da vacinação contra o coronavírus, tem sido possível o retorno cauteloso das atividades de ensino para os câmpus universitários, efetuado de forma gradual, enquanto que as instituições de educação superior 
estão utilizando do formato de ensino híbrido para atender as exigências de saúde e, ao mesmo tempo, os anseios de volta às atividades presenciais, embora, em muitos casos, isso ainda represente risco, especialmente, no Brasil, que sequer temos $70 \%$ da população vacinada.

Assim, não é só no cenário de trabalho remoto e de ensino através de plataformas digitais que se pode vislumbrar riscos aos direitos da personalidade e aos dados pessoais dos docentes do ensino superior privado, mas também enquanto subsistir esta alternância de trabalho, ora em casa, ora nas dependências das instituições de ensino.

Isso representa um cenário de instabilidade para os professores, haja vista o dever de retorno ao ambiente da instituição de ensino, em determinados dias, a fim de dar aulas para certa parcela das turmas, seguindo-se de outros dias em que a aula deve ser ministrada, ainda, de forma remota, com a disponibilização das gravações para a instituição de ensino, e para os alunos que não possam comparecer presencialmente.

Variados direitos se encontram suscetíveis de violação nas situações como a descrita, habituais na vivência dos professores, tendo em vista que a gravação de uma aula envolve a imagem, liberdade de cátedra, e a produção intelectual, entre outros diversos atributos e dados pessoais dos professores que são disponibilizados em favor das instituições de ensino, empregadoras, correndo riscos de serem utilizadas arbitrariamente, como estudiosas apontam:

\footnotetext{
Indaga-se, por exemplo, por quanto tempo as aulas gravadas devem ficar disponíveis para acesso de estudantes, e se a remuneração do trabalho docente não deveria ser complementada em razão da utilização do material de aula produzido pelo(a) professor(a) em outros semestres e cursos, e também em razão do aumento na quantidade de alunos nas salas virtuais, o que demanda mais tempo de trabalho para atendimento de dúvidas e correção de atividades. (DELGADO; PESSANHA; ROCHA, 2021)
}

Referidas preocupações são cabíveis, pois modificaram-se as formas de realização da docência, entretanto, não se modificaram os principais e indispensáveis instrumentos de trabalhos utilizados pelos professores: seus corpos e mentes. Quer em presença física, quer em presença virtual, por detrás das telas eletrônicas, o professor continua empenhando sua voz e sua imagem em seu labor, assim como sua autonomia e seus esforços intelectuais. Ademais, o elevado número de alunos nas salas virtuais, triplicam as atividades "extraclasse", com inúmeras provas e trabalhos para a correção. Isso, também, é fator de impacto no direito à desconexão do docente que, não raras vezes, para cumprir os prazos impostos pelas 
instituições de ensino, para corrigir as provas, tem que permanecer até sem dormir, prejudicando, evidentemente, a sua saúde.

Além de consistir em um direito da personalidade, a imagem, assim como a saúde, é um direito fundamental considerado inviolável, segundo o artigo $5^{\circ}$, inciso $\mathrm{X}$, da Constituição Federal, de 1988. Tal proteção garante que o uso desautorizado é passível de indenização, visto que a imagem da pessoa consiste em um "conjunto de caracteres que a identifica no meio social [...] é o vínculo que une uma pessoa à sua expressão externa" (BITTAR, 2015, p. $153)$.

No caso dos professores, assim como o nome, é necessário que seja acordada uma licença para uso de imagem, consentindo com sua utilização pelas instituições de ensino (SILVA; PEREIRA, 2013 p.129), inclusive por representar a figura do professor para o meio social, e influenciar em seu trabalho.

Por sua vez, o direito à intimidade e à privacidade visam proteger a pessoa de intromissões alheias, e no que tange ao Direito do Trabalho, tais direitos podem vir a se contrapor ao poder diretivo do empregador, e às necessidades de execução do contrato de trabalho. Todavia, aponta-se que esse poder encontra limitações, para que não importem em violação aos direitos da personalidade e aos demais direitos.

Neste ponto, adentra-se a outra questão atinente ao trabalho docente, que é a liberdade de cátedra, ou seja, a autonomia para a condução das disciplinas e a capacidade dos docentes de administrarem o ambiente da sala de aula, em relação aos discentes, entre outras atribuições exclusivas do professor, sendo certo que tal direito também é assegurado constitucionalmente, pelo artigo 206, da Constituição Federal, de $1988^{6}$, porque além de se configurar como um direito individual dos professores, representa um instrumento do direito de aprender dos alunos, e de acesso à educação (RODRIGUES; MAROCCO, 2014). Neste sentido, ensinam as estudiosas Leda Maria Messias da Silva e Marice Taques Pereira (2013, p. 139):

o contrato de trabalho já é firmado tendo como base a confiança e para chegar à
admissão existem processos seletivos que avaliam a capacidade técnica e didática do
professor. A filmagem em sala de aula é transformar uma Instituição de Ensino em
quartel-general [...] que, além de ferirem a liberdade de cátedra do professor, não se
coadunam com os princípios que primam pela dignidade no ambiente de trabalho.

\footnotetext{
${ }^{6}$ Art. 206. O ensino será ministrado com base nos seguintes princípios: [...] II - liberdade de aprender, ensinar, pesquisar e divulgar o pensamento, a arte e o saber; III - pluralismo de ideias e de concepções pedagógicas, e coexistência de instituições públicas e privadas de ensino; [...] (BRASIL, 1988)
} 
Sendo assim, entende-se que as gravações das aulas dos professores podem ser consideradas mecanismos alternativos pertencentes ao ensino remoto, por meio de plataformas digitais, como utilizadas em razão da emergência de saúde pública causada pelo coronavírus, porém, mostra-se inadequado que sejam exigidas durante o regime de trabalho híbrido, ou até mesmo após o retorno definitivo ao meio presencial, uma vez que resultariam em violações aos direitos da personalidade e aos direitos fundamentais de imagem, da intimidade e privacidade dos professores, além de ferirem sobremaneira o direito à liberdade de cátedra.

No que diz respeito aos referidos atributos da personalidade, cabe sinalizar, por último, que outra proteção normatizada que os abrange pelo ordenamento jurídico brasileiro, e deve ser observada até mesmo nas relações trabalhistas, é a Lei Geral de Proteção de Dados (LGPD, Lei $\mathrm{n}^{\circ}$ 13.709, de 2018), porquanto o professor é considerado titular de dados pessoais e sensíveis em tratamento pelas instituições de ensino. Mesmo que, neste caso, o tratamento de dados ocorra sob a base legal de execução de contrato de trabalho, os dados dos professores devem ser protegidos enquanto pessoas naturais, titulares de direitos individuais, tais como os direitos da personalidade e os direitos fundamentais, para que em última análise, seja resguardada sua dignidade, também na relação laborativa, vedando-se abusos.

Não se olvida que o ensino remoto e o ensino híbrido são situações distintas, porém, que vem sendo empregadas como uma resposta ao estado de calamidade pública causado pelo coronavírus. Assim, como uma resposta rápida à pandemia, justifica-se a relativização de algumas condições de trabalho (como a mudança temporária para o meio virtual, que invariavelmente dependem de disponibilização da imagem e dos dados dos professores), até mesmo para o resguardo da vida e saúde dos trabalhadores, assim como para a manutenção dos contratos de emprego e das atividades educacionais.

Todavia, urge cautela para a tomada de tais medidas e limites na sua execução ao exagerar na cobrança de aulas, totalmente, síncronas, bem como relacionadas ao prospectivo retorno às atividades presenciais, sendo imprescindível a adequada regulamentação dos contratos individuais de trabalho, com a observância dos limites legais impostos, para que tais modificações não extrapolem barreiras intransponíveis e gerem danos às garantias fundamentais e aos direitos da personalidade dos profissionais da educação.

O trabalho remoto, portanto, pode inserir a atividade dos professores em condição de potenciais riscos aos direitos da personalidade, porquanto os docentes tem desempenhado 
funções demandadas especificamente pelo teletrabalho, ou pelo trabalho híbrido, cujas condições não se encontram adequadamente pactuadas, subjugando os professores a um trabalho demasiadamente exaustivo e mal remunerado, em detrimento de suas próprias imagens, de sua privacidade, de seus dados pessoais e da liberdade de cátedra.

Constata-se que os professores estão submetidos a grandes inseguranças laborativas, no cenário durante e pós pandêmico, uma vez que necessitam cumprir com as suas atividades profissionais, embora enfrentam calados uma série de violações e fragilizações de seus direitos, além das inseguranças relacionadas à saúde e segurança pessoal geradas pelo coronavírus.

Ressalta-se, por fim, que as novas situações experienciadas pelos docentes, em razão da crescente tecnológica no ensino e das formas virtuais de trabalho, trouxeram novos olhares e perspectivas para as atividades desenvolvidas pelos profissionais da educação superior privada, demandando a adequação das normas trabalhistas, aliada à correta execução dos contratos individuais de trabalho, a fim de que se sejam observadas as novas nuances impostas para o trabalho docente, resguardando os direitos da personalidade e os demais direitos garantidos aos professores.

\section{CONCLUSÕES}

A chegada da pandemia criou a necessidade de adoção de medidas rápidas e eficazes para o combate à disseminação do coronavírus, dentre as quais houve a migração repentina do ensino presencial para o ensino remoto, resultando em modificações nas formas de praticar a atividade laborativa dos professores e professoras.

Diante deste cenário, a presente pesquisa se propôs a analisar algumas das principais condições que precarizam o trabalho docente nas instituições de ensino superior privadas, intensificadas pela implementação do trabalho remoto, em razão da pandemia causada pelo coronavírus, e seus impactos nos direitos da personalidade inerentes aos docentes, tais como o direito à imagem, à intimidade, à privacidade e proteção de dados, e a liberdade de cátedra.

Assim, pontua-se que antes mesmo da crise sanitária, sobretudo nas instituições de ensino superior privadas, o trabalho docente se encontrava precarizado, por adversidades como o medo do desemprego massivo, em face do "empresariamento da educação" (tendência 
capitalista que, em suma, visa a lucratividade por meio da redução de custos, e fomenta a educação à distância), e da fragmentação da atividade dos professores.

Ainda, a ausência do ambiente físico e da proximidade com os educandos provocou um afastamento dos educadores de sua função formadora, desvirtuando ainda mais a finalidade e o sentido da docência: transmitir conhecimentos com qualidade e submeteu o professor ao excesso de trabalho, com salas virtuais demasiadamente lotadas e sem direito à desconexão.

Observa-se, portanto, que a implementação emergencial do trabalho e do ensino remoto intensificou condições adversas no trabalho de professores, no que diz respeito à dificuldade em se desconectar do trabalho, bem como à necessidade de qualificação tecnológica para ensinar virtualmente, e quanto à aquisição, muitas vezes com recursos próprios, de instrumentos de trabalho para a instalação do ambiente de trabalho dentro de suas próprias casas, como internet, mobiliário, dentre outros, além da inadequação dos contratos de trabalho, que comportassem as novas situações e demandas próprias do trabalho remoto.

Ressalta-se que além de mudanças nas práticas docentes, houve uma mudança significativa no meio de trabalho dos professores, posto que suas próprias residências passaram a ser local de execução das atividades laborativas, cabendo a garantia de direitos assegurados pelo ordenamento jurídico brasileiro.

Constata-se, ainda, que o emprego do ensino híbrido, alternado com o home office gera condição de instabilidade ao trabalho docente, no que diz respeito aos direitos da personalidade, sendo que as gravações das aulas podem ser consideradas próprias e inerentes ao ensino remoto, porém, foram estendidas para além do ensino remoto, sem respeito ao direito de imagem e à liberdade de cátedra docente.

Portanto, ao se tratar de ensino híbrido ou o modo presencial, entende-se que as gravações das aulas no ensino remoto, serviram de pretexto para estendê-las para além das salas virtuais e podem ferir direitos da personalidade, como o direito à imagem, à privacidade e aos dados pessoais dos professores, além de configurarem abuso e afronta à liberdade de cátedra dos docentes, como bem se destacou.

Conclui-se, por fim, que apesar da necessidade da adoção de medidas rápidas, em resposta à pandemia, é fundamental que se observem as limitações impostas às instituições de ensino, empregadoras, sendo imprescindível que se observem as normas constitucionais, justrabalhistas, além das determinações advindas da própria Lei Geral de Proteção de Dados, 
na execução dos contratos de trabalho dos docentes, profissionais essenciais para o desenvolvimento de toda sociedade e que sofrem com a precarização de sua profissão. Essencial, também, o respeito ao direito à saúde do docente, a fim de estancar de imediato a precarização no meio ambiente de trabalho deste, pois a educação de qualidade é um direito de todos e deste respeito aos direitos da personalidade dos docentes é que dependerá a qualidade da educação no futuro. 


\section{REFERÊNCIAS}

BITTAR, Carlos Alberto. Os direitos da personalidade. 8 ed. São Paulo: Saraiva, 2015.

BRASIL. Constituição da República Federativa do Brasil de 1988. Disponível em: http://www.planalto.gov.br/ccivil_03/constituicao/constituicaocompilado.htm. Acesso em: 30 ago. 2021.

BRASIL. Decreto-Lei 5.452 de $1^{\circ}$ de maio de 1943. Consolidação das Leis do trabalho, Brasília, DF. Disponível em: http://www.planalto.gov.br/ccivil_03/decreto-lei/del5452.htm. Acesso em 4 set. 2021.

BRASIL. Medida provisória n⿳ 927, de 22 de março de 2020. Diário Oficial [da] República Federativa do Brasil, Brasília, DF. Disponível em: http://www.planalto.gov.br/ccivil_03/_ato 2019-2022/2020/mpv/mpv927.htm. Acesso em: 4 set. 2021.

BRASIL. Lei no 13.709, de 14 agosto de 2018. Lei Geral de Proteção de Dados Pessoais (LGPD). Diário Oficial, Brasília, 2018. Disponível em: http://www.planalto.gov.br/ccivil_03/ _ato2015-2018/2018/lei/L13709.htm. Acesso em: 29 ago. 2021.

CARMO, Renata de Oliveira Souza; FRANCO, Aléxia Pádua. Da docência presencial à docência online: aprendizagens de professores universitários na educação a distância.

Educação em Revista, Belo Horizonte, v. 35, p. 1-29, 2019. DOI:

http://dx.doi.org/10.1590/0102-4698210399.

DELGADO, Gabriela Neves; PESSANHA, Vanessa Vieira; ROCHA, Ana Luísa Gonçalves. Desafios do trabalho docente universitário privado no contexto pandêmico. Revista de Direito do Trabalho e Seguridade Social. São Paulo, SP, vol. 216, ano 47, p. 161-183, mar./abr. 2021. Disponível em: https://hdl.handle.net/20.500.12178/183010. Acesso em: 28 ago. 2021.

DELGADO, Maurício Godinho. Direitos fundamentais na relação de trabalho. Revista de Direitos e Garantias Fundamentais, Vitória, n. 2, p. 11-40, 2007. Disponível em: https://doi.org/10.18759/rdgf.v0i2.40. Acesso em: 29 ago. 2021.

GAULEJAC, V. (2007) Gestão como doença social: ideologia, poder gerencialista e fragmentação social. São Paulo: Ideias e Letras.

GEMELLI, Catia Eli; CERDEIRA, Luísa. Covid-19: impactos e desafios para a educação superior brasileira e portuguesa. In: GUIMARÃES, Ludmila de Vasconcelos M.;

CARRETEIRO, Teresa Cristina; NASCIUTTI, Jacyara Rochael (org.). Janelas da pandemia. Belo Horizonte: Editora Instituto DH, 2020. p. 115-124.

GUIMARÃES, Ludmila de Vasconcelos M.; CARRETEIRO, Teresa Cristina; NASCIUTTI, Jacyara Rochael (org.). Janelas da pandemia. Belo Horizonte: Editora Instituto DH, 2020. $500 \mathrm{p}$. 
KLAUS, Viviane. Empresariamento da educação em tempos de capitalismo flexível: análise de parcerias escola/empresa no rs. Educação Unisinos, v. 21, n. 3, p. 345-355, set./dez. 2017. Disponível em: http://dx.doi.org/10.4013/edu.2017.213.08. Acesso em: 3 set. 2021.

MILL, D. Docência virtual: uma visão crítica. Campinas: Papirus, 2012 apud CARMO, Renata de Oliveira Souza; FRANCO, Aléxia Pádua. Da docência presencial à docência online: aprendizagens de professores universitários na educação a distância. Educação em Revista, Belo Horizonte, v. 35, p. 1-29, 2019. DOI: http://dx.doi.org/10.1590/01024698210399.

MEDEIROS, B. \& SIQUEIRA, M. (2019). Relações de Confiança e sua Instrumentalização no Controle de Docentes em IES Privadas. REAd. Revista Eletrônica de Administração. Porto Alegre, 25(1), 213-237. DOI:10.1590/1413-2311.241.90087

MELLO, Álvaro. Teletrabalho (telework): o trabalho em qualquer lugar e qualquer hora. Rio de Janeiro: Qualitymark, 1999, p. 4.

OLIVEIRA, Leonardo Alexandre Tadeu Constant de; LEMOS JUNIOR, Eloy Pereira. A educação a distância, o teletrabalho e o direito: os profissionais da docência na educação virtual. Revista Univap, v. 24, n. 45, p. 17-33, 2018. Disponível:

http://revista.univap.br/index.php/revistaunivap/article/view/2006. Acesso em: 6 dez. 2021.

PESSANHA, Vanessa Vieira. A docência em instituições privadas de ensino superior no Brasil do século XXI: desafios e perspectivas para a efetivação do direito fundamental ao trabalho digno. In: DELGADO, Gabriela Neves (coord.). Direito fundamental ao Trabalho Digno no Século XXI: desafios e reinterpretações para as relações de trabalho rurais, urbanas e de serviços. São Paulo: Editora LTr, 2020. Cap. 14. p. 218-229. (Trabalho, constituição e cidadania; v. 2).

RABELLO, Ana Maria Valle; SOUZA, Carolina Rodrigues Alves de; MARTINS, Luciana Rodrigues. Educação remota em tempos de Covid-19. In: GUIMARÃES, Ludmila de Vasconcelos M.; CARRETEIRO, Teresa Cristina; NASCIUTTI, Jacyara Rochael (org.). Janelas da pandemia. Belo Horizonte: Editora Instituto DH, 2020. p. 101-113.

RODRIGUES, Horácio Wanderlei; MAROCCO, Andréa de Almeida Leite. Liberdade de cátedra e a Constituição Federal de 1988: alcance e limites da autonomia docentes. In: CAÚLA, Bleine Queiroz et al. Diálogo ambiental, constitucional e internacional. Fortaleza: Premius, 2014. v. 2. p. 213-238.

SILVA, Leda Maria Messias da; PEREIRA, Marice Taques. Docência (In)digna: o meio ambiente laboral do professor e as consequências em seus direitos da personalidade. São Paulo, SP, LTr, 2013.

SILVA, Leda Maria Messias da; ZANIN, Maria Judith Fernandes Coelho. A inversão do ônus da prova como garantia dos direitos da personalidade em relação à saúde do trabalhador acometido pelas doenças profissionais. Trabalho publicado em Anais do xxi Encontro Nacional do CONPEDI, 2012. Disponível em: http://www.publicadireito.com.br/artigos/ ?cod=496e05e1aea0a9c4. Acesso em: 6 set. 2021. 